\title{
Oral morphine versus ibuprofen administered at home for postoperative orthopedic pain in children: a randomized controlled trial
}

\author{
Naveen Poonai MD, Natasha Datoo MD, Samina Ali MDCM, Megan Cashin MD, Amy L. Drendel MD, \\ Rongbo Zhu MD, Natasha Lepore BSc, Michael Greff MD, Michael Rieder MD, Debra Bartley MD
}

Cite as: CMAJ 2017 October 10;189:E1252-8. doi: 10.1503/cmaj.170017

\begin{abstract}
BACKGROUND: Oral morphine for postoperative pain after minor pediatric surgery, while increasingly popular, is not supported by evidence. We evaluated whether oral morphine was superior to ibuprofen for at-home management of children's postoperative pain.
\end{abstract}

METHODS: We conducted a randomized superiority trial comparing oral morphine $(0.5 \mathrm{mg} / \mathrm{kg})$ with ibuprofen $(10 \mathrm{mg} / \mathrm{kg})$ in children 5 to 17 years of age who had undergone minor outpatient orthopedic surgery (June 2013 to September 2016). Participants took up to 8 doses of the intervention drug every 6 hours as needed for pain at home. The primary outcome was pain, according to the Faces Pain Scale - Revised, for the first dose. Secondary outcomes included additional analgesic requirements, adverse effects, unplanned health care visits and pain scores for doses 2 to 8 .

RESULTS: We analyzed data for 77 participants in each of the morphine and ibuprofen groups. Both interventions decreased pain scores with no difference in efficacy. The median difference in pain score before and after the first dose of medication was 1 (interquartile range $0-1$ ) for both morphine and ibuprofen $(p=0.2)$. For doses 2 to 8 , the median differences in pain score before and after the dose were not significantly different between groups. Significantly more participants taking morphine reported adverse effects (45/65 [69\%] v. 26/67 [39\%], $p<0.001$ ), most commonly drowsiness (31/65 [48\%] v. $15 / 67$ [22\%] in the morphine and ibuprofen groups, respectively; $p=0.003$ ).

INTERPRETATION: Morphine was not superior to ibuprofen, and both drugs decreased pain with no apparent difference in efficacy. Morphine was associated with significantly more adverse effects, which suggests that ibuprofen is a better first-line option after minor surgery. Trial registration: ClinicalTrials. gov, no. NCT01686802.
M

oderate to severe pain is the most common postoperative pediatric complaint, ${ }^{1}$ particularly within 24 hours $^{2}$ and even after minor surgery. ${ }^{3-7}$ Inadequate analgesia is prevalent after outpatient pediatric surgery ${ }^{3,6-10}$ and is the most common reason for unplanned hospital admissions. ${ }^{11}$ In children, suboptimal analgesia can result in sleep disturbance, behavioural changes and vomiting. ${ }^{12}$ Untreated pain leads to slower wound healing, ${ }^{13}$ needle phobia, ${ }^{14}$ hyperesthesia ${ }^{15}$ and fear of medical procedures. ${ }^{16}$

Undertreatment is an important cause of inadequate postoperative analgesia. ${ }^{17-20}$ Both ibuprofen ${ }^{21,22}$ and oral morphine ${ }^{22,23}$ have shown benefit in children with musculoskeletal injuries. Following deaths of children who received codeine postoperatively, ${ }^{24,25}$ the United States Food and Drug Administration $^{26}$ and Health Canada ${ }^{27}$ issued advisories. Orthopedic procedures are associated with the highest incidence of postdischarge pain. ${ }^{28,29}$ Although not discipline-specific, more than $80 \%$ of pediatric surgeries are performed on an outpatient basis, ${ }^{30}$ which renders pain management largely the responsibility of caregivers at home. Oral morphine and other opioids are being prescribed more often. ${ }^{31-33}$ However, evidence supporting morphine for at-home postoperative pain management in children is lacking.

Given the lack of consensus standards for analgesia after pediatric outpatient surgery, suboptimal provision of analgesia ${ }^{2,9}$ and growing fears about opioids, there is an urgent need for evidence to guide outpatient analgesic choices for children at discharge. We sought to evaluate whether oral morphine was superior to ibuprofen for relieving children's pain at home, after minor outpatient orthopedic surgery. 


\section{Methods}

\section{Design and setting}

For this parallel-group, randomized, blinded superiority trial, we recruited participants from June 2013 to September 2016 at the Children's Hospital, London Health Sciences Centre, London, Ontario, where about 150 pediatric outpatient orthopedic surgeries are performed annually. A data and safety monitoring board convened at $25 \%, 50 \%$ and $75 \%$ recruitment to monitor adverse effects.

\section{Participants}

We included all children aged 5 to 17 years who presented to the pediatric orthopedic clinic and were scheduled for minor outpatient surgery. We excluded children with known hypersensitivity to ibuprofen or morphine, long-term use of nonsteroidal anti-inflammatory drugs (NSAIDs) or opioids, renal insufficiency, bleeding disorder, cognitive impairment, obstructive sleep apnea, regional anesthesia or pregnancy.

Patients were screened consecutively for eligibility by a research assistant, who obtained informed consent and assent from all participants or their legal guardians, and who performed all study-related correspondence with participants.

\section{Interventions}

The hospital pharmacy performed randomization, using a computer-based random number generator (www.randomization. com). Eligible participants were randomly assigned in a 1:1 allocation ratio using a block size of 4 or 6 to receive either standardrelease oral morphine $(0.5 \mathrm{mg} / \mathrm{kg}$, maximum $20 \mathrm{mg}$ ) or oral ibuprofen $(10 \mathrm{mg} / \mathrm{kg}$, maximum $600 \mathrm{mg}$ ) every 6 hours as needed for pain, for a total of 48 hours after discharge (maximum 8 doses). Allocation was concealed through use of sequentially numbered, opaque sealed envelopes. Study medications and placebos were kept in identical opaque sealed bottles and were dispensed in identical white plastic vials. Because of differences in taste and consistency, we employed a double-dummy approach ${ }^{34}$ whereby each participant was given 8 prepackaged doses consisting of 2 vials (morphine and placebo ibuprofen or placebo morphine and ibuprofen). The placebos were identical in taste, colour and consistency to their active drug counterparts, so that participants were unaware of which intervention they were receiving. A protocol for unmasking was available on an emergency basis. Participants were asked to take a second dose if they vomited within 30 minutes of the first. For pain persisting longer than 60 minutes after the intervention, participants were instructed to take acetaminophen $15 \mathrm{mg} / \mathrm{kg}$ (maximum of $975 \mathrm{mg}$ ).

Participants recorded their pain using the Faces Pain Scale Revised ${ }^{35}$ at discharge and at home (immediately before and $30 \mathrm{~min}$ after each dose). Thirty minutes is the time to a clinically significant reduction in pain, ${ }^{23,36}$ to peak plasma concentration for oral morphine ${ }^{37}$ and to onset of analgesia for ibuprofen. ${ }^{38}$ Consistent with the described use of the Faces Pain Scale Revised, ${ }^{39}$ we instructed all children to circle the face on the horizontal axis that corresponded to their pain level. We asked caregivers to supervise their children to ensure that only 1 face was circled at each time point. Caregivers and participants also recorded the number of acetaminophen doses taken for pain and any adverse effects that occurred within 96 hours of the first dose (selected from a list of known adverse effects).

Participants returned data collection forms by mail, using a stamped, self-addressed envelope, and returned unused medication to the study coordinator at the follow-up orthopedic clinic visit. We corroborated the reported number of doses taken with the medication that remained on the follow-up visit. We contacted participants whose forms contained unclear information. Discrepancies were resolved by discussion with the caregivers. A research assistant entered data from the forms into a studyspecific Excel spreadsheet. Participants received a phone call at 24, 48, 72 and 96 hours after discharge to inquire about severe adverse events and unscheduled visits to a health care provider. Participants, caregivers and all members of the research team were blinded to the interventions.

Anesthesia and analgesia before discharge were provided as per the standard of care at our institution. Intraoperatively, participants received a weight-based dose of fentanyl and propofol with or without lidocaine for induction and sevoflurane for maintenance of anesthesia. At the end of the case, each participant received a subcutaneous injection of $2-5 \mathrm{~mL}$ of $1 \%$ lidocaine around the incision site. In the postanesthetic care unit, each participant received a weight-based dose of acetaminophen or, if the patient was in more severe pain, intravenous (IV) morphine.

\section{Outcome measures}

The primary outcome was the pre-post difference in selfreported pain for the first dose, based on the pain scale. ${ }^{35}$ The Faces Pain Scale - Revised has been validated for postoperative use ${ }^{40}$ in children from 4 to 12 years of age ${ }^{39}$ and is believed to be clinically useful for older children. ${ }^{41}$ Although not validated for home use, the scale has been used at home for fracture pain ${ }^{22}$ and postoperative pain, ${ }^{2}$ is preferred by children, ${ }^{40}$ does not require training ${ }^{42}$ and was easily interpretable across our sample's age range. ${ }^{41}$ The 6-item Faces Pain Scale - Revised is scored from 0 (no pain) to 10 (maximum pain), with severity defined as none (0 or 2), mild (4), moderate (6) or severe (8 or 10$).{ }^{43}$ Secondary outcomes included the pre-post difference in pain for the second to eighth doses (also based on the pain scale), the number of participants requiring breakthrough acetaminophen for pain, unscheduled visits to a health care provider for pain within 96 hours of the first dose and adverse effects.

\section{Statistical analysis}

We analyzed between-group differences in pain scores using an intention-to-treat analysis, based on the assumption that for participants who received no study intervention, the pre-post difference in pain scores would be zero. A difference in pain intensity of 1 face on the Faces Pain Scale - Revised has been shown to be a minimal clinically important difference. ${ }^{43,44}$ We analyzed the between-group differences in pain scores using the Wilcoxon 2-sample test. We used a mixed linear regression model, with an unstructured covariance matrix, to assess between-group differences in pain scores across all doses over time. We used the 
Pearson $\chi^{2}$ test or Student $t$ test to evaluate differences in acetaminophen use and adverse effects. The study was powered to detect a between-group difference in the primary outcome. Assuming a standard deviation of 2 faces, ${ }^{39,41} 63$ children per group were required to detect a between-group difference of 1 face at the 5\%, 2-sided level of significance with $80 \%$ power. ${ }^{45}$ We used SPSS software, version 23 (IBM). We considered $p$ values less than 0.05 to be statistically significant.

\section{Ethics approval}

This trial was approved by the Health Sciences Research Ethics Board of Western University.

\section{Results}

\section{Participants}

We report results of an intention-to-treat analysis of 154 participants, of whom 71 (46\%) were female (Figure 1, Table 1). The mean age was 12.4 (standard deviation [SD] 3.5) years. The overall mean pain score at discharge was 2.3 (SD 1.3) (Table 1). No participants were lost to follow-up. Eight participants withdrew after randomization because they believed that ibuprofen would not adequately manage pain. Thirteen participants did not take any study medication, and all of these reported that the pain had not been sufficiently severe. All study vials were returned, and all opened vials were empty. For all but 1 participant, the number of used vials corresponded to the information on the data collection form. For the 1 exception, the participant reported a single pair of pain scores independent of analgesic administration. There were no obvious between-group differences in surgical procedures performed. No participants received intra-articular analgesia, regional analgesia, clonidine or long-acting analgesics. Three participants ( 2 in the morphine group and 1 in the ibuprofen group) received a single dose of IV morphine $0.05 \mathrm{mg} / \mathrm{kg}$ in the postanesthetic care unit. The demographic characteristics of participants who underwent randomization and did not take any study medication are presented in Table 2.

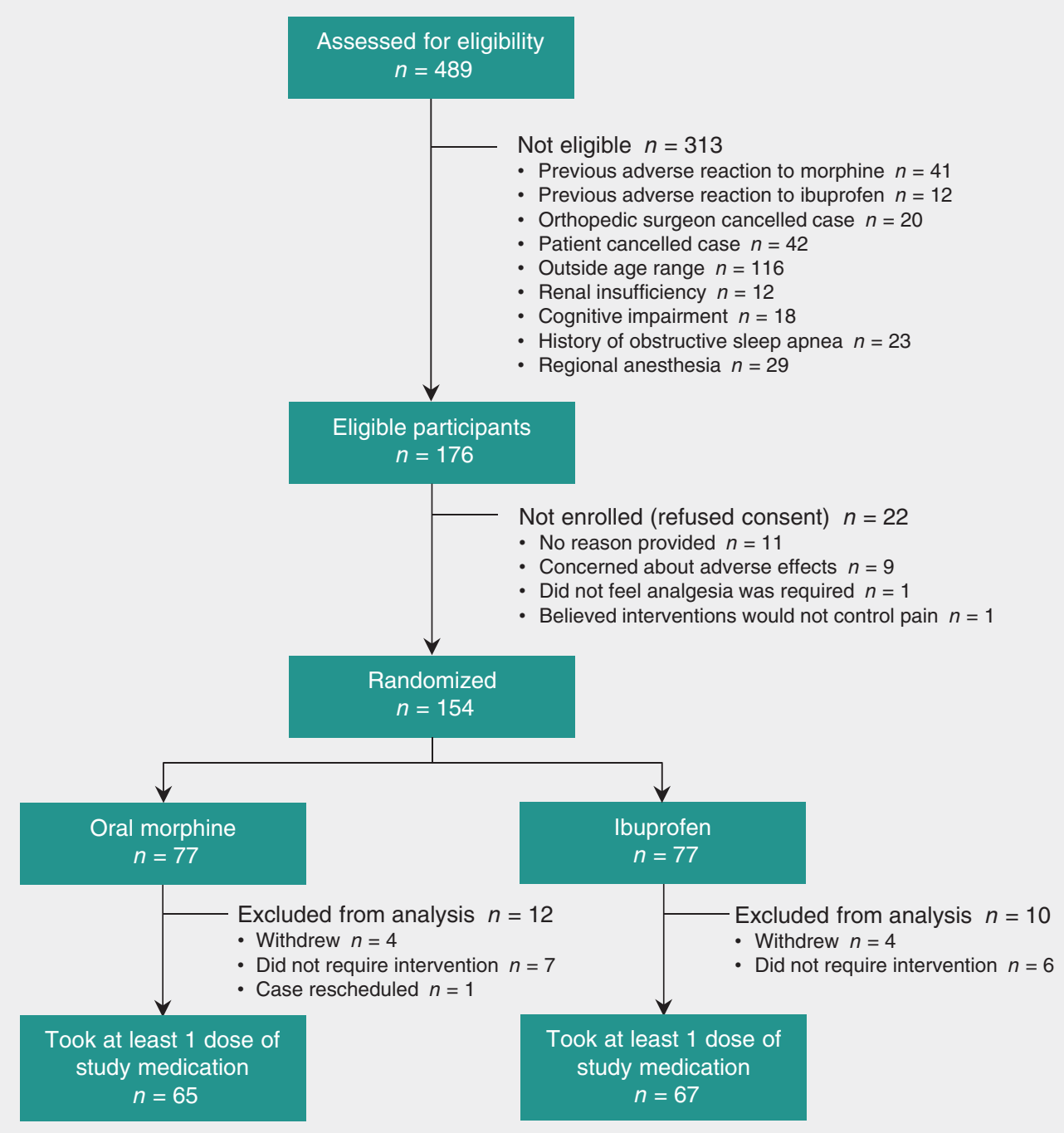

Figure 1: Flow of participants through the trial. 


\section{Primary outcome}

The median time to the first dose was 3.3 (interquartile range [IQR] 0.5-6) hours for the morphine group and 3.5 (IQR 1-6) for the ibuprofen group. There were no significant differences between groups in the change in pain scores for the first dose $(p=0.2)$ (Table 3$)$. There were no significant between-group differences in pain scores over time $(p=0.4)$.

\section{Secondary outcomes}

Sixty-five (84\%) and $67(87 \%)$ of participants took at least 1 dose of oral morphine or ibuprofen, respectively. There were

Table 1: Demographic characteristics of participants

\begin{tabular}{|c|c|c|}
\hline \multirow[b]{2}{*}{ Characteristic } & \multicolumn{2}{|c|}{ Medication; no. (\%) of participants } \\
\hline & $\begin{array}{l}\text { Oral morphine } \\
\qquad n=77\end{array}$ & $\begin{array}{c}\text { Ibuprofen } \\
n=77\end{array}$ \\
\hline Age, $y r$, mean \pm SD & $12.7 \pm 3.6$ & $12.1 \pm 3.5$ \\
\hline Sex, female & $32(42)$ & $39(51)$ \\
\hline \multicolumn{3}{|l|}{ No. of doses taken } \\
\hline 0 & $12(16)$ & $10(13)$ \\
\hline 1 & $4(5)$ & $8(10)$ \\
\hline 2 & $9(12)$ & $5(6)$ \\
\hline 3 & $10(13)$ & $7(9)$ \\
\hline 4 & $10(13)$ & $9(12)$ \\
\hline 5 & $5(6)$ & $6(8)$ \\
\hline 6 & $6(8)$ & $7(9)$ \\
\hline 7 & $5(6)$ & $5(6)$ \\
\hline 8 & $16(21)$ & $20(26)$ \\
\hline \multicolumn{3}{|l|}{ Type of procedure } \\
\hline Arthroscopy & $9(12)$ & $10(13)$ \\
\hline ORIF & $13(17)$ & $16(21)$ \\
\hline Ankle & 2 & 2 \\
\hline Radial neck & 1 & 3 \\
\hline Elbow & 9 & 10 \\
\hline Ulna & 1 & 1 \\
\hline Epiphysiodesis & $2(3)$ & $2(3)$ \\
\hline Cyst excision & $7(9)$ & $7(9)$ \\
\hline Hardware removal & $38(49)$ & $34(44)$ \\
\hline Biopsy & $1(1)$ & 0 \\
\hline Tendon or ligament repair & $2(3)$ & $5(6)$ \\
\hline Percutaneous pinning & $1(1)$ & $1(1)$ \\
\hline Suture removal & 0 & $1(1)$ \\
\hline Amputation revision & $1(1)$ & 0 \\
\hline ORIF + epiphysiodesis & $2(3)$ & 0 \\
\hline Steroid injection & $1(1)$ & $1(1)$ \\
\hline $\begin{array}{l}\text { Discharge pain score, } \\
\text { mean } \pm \text { SD }\end{array}$ & $2.4 \pm 1.3$ & $2.3 \pm 1.5$ \\
\hline
\end{tabular}

no significant differences in the change in pain scores for doses 2 to 8 . However, both morphine and ibuprofen produced a decrease in pain scores with each dose (Table 3 ). There was no significant difference in the number of participants who required acetaminophen for breakthrough pain $(p=0.2)$. Among participants who took acetaminophen, there was no significant difference in the number of acetaminophen doses taken per participant $(p=0.09)$ (Table 4$)$. Significantly more participants in the morphine group than in the ibuprofen group experienced adverse effects (45/65 [69\%] v. 26/67 [39\%], $p<$ 0.001 ; Table 4). There were no serious adverse events, deaths, unscheduled visits to a health care provider for pain or adverse events, or unmasking of the intervention.

\section{Interpretation}

In this trial of at-home pain management in children who underwent minor orthopedic surgery, both oral morphine and ibuprofen reduced pain with no apparent difference in analgesic efficacy. Most of the children experienced pain severe enough to require analgesia. Oral morphine was associated with significantly more adverse effects, which suggests that ibuprofen is a safer first-line analgesic.

Among children who have undergone ambulatory surgery, oral morphine has not been studied for at-home therapy, nor has it been compared with ibuprofen, a frequently used analgesic. Our results are consistent with those from a study of children with nonoperative fractures in which oral morphine produced analgesia comparable to that with ibuprofen but had significantly more adverse effects. ${ }^{22}$ In children remaining in hospital after surgery, several studies have found that parenteral ${ }^{46}$ and oral morphine $e^{47,48}$ did not produce better analgesia than active comparators. Our findings contribute to this evidence, because we have shown that after discharge from ambulatory surgery, oral morphine has no analgesic advantage over ibuprofen for first-line treatment of pain.

Table 2: Characteristics of participants according to whether data were included in analysis*

\begin{tabular}{|c|c|c|c|}
\hline \multirow[b]{2}{*}{ Characteristic } & \multicolumn{3}{|c|}{ Participant group; no. (\%) of participants $†$} \\
\hline & $\begin{array}{l}\text { Included in } \\
\text { ITT analysis } \\
n=154\end{array}$ & $\begin{array}{c}\text { Did not take } \\
\text { study drug } \\
\quad n=13\end{array}$ & $\begin{array}{c}\text { Withdrew } \\
\text { after randomization } \neq \\
n=8\end{array}$ \\
\hline $\begin{array}{l}\text { Age, yr, } \\
\text { mean } \pm \text { SD }\end{array}$ & $12.4 \pm 3.5$ & $10.8 \pm 3.9$ & $12 \pm 4.4$ \\
\hline Sex, female & $71(46)$ & $5(38)$ & $4(50)$ \\
\hline \multicolumn{4}{|l|}{ Group assignment } \\
\hline Oral morphine§ & $77(50)$ & $7(54)$ & $4(50)$ \\
\hline Ibuprofen & $77(50)$ & $6(46)$ & $4(50)$ \\
\hline \multicolumn{4}{|c|}{$\begin{array}{l}\text { Note: ITT = intention-to-treat, SD = standard deviation. } \\
{ }^{*} \text { Data were included in the analysis if the participant took at least } 1 \text { dose of the study } \\
\text { medication. } \\
\text { †Except where indicated otherwise. } \\
\text { †Participants who withdrew after randomization but before receiving any study } \\
\text { medication. } \\
\text { §One participant in the oral morphine group was excluded from the analysis because } \\
\text { the operative case was cancelled by the surgeon after randomization. }\end{array}$} \\
\hline
\end{tabular}


In contrast to our findings that ibuprofen was associated with clinically significant pain reduction, ${ }^{39}$ a systematic review of NSAIDs for children in the postanesthetic care unit suggested otherwise. ${ }^{49}$ Unlike patients receiving care in hospital, our sample included children who underwent minor surgeries that may not have been associated with severe pain ${ }^{43}$ and who may have experienced less distress in their home environment. Among

Table 3: Pain scores before and after each dose of pain medication, according to the Faces Pain Scale - Revised, and difference in score

Study medication; median value (IQR)

\begin{tabular}{|c|c|c|c|}
\hline Pain measurement & $\begin{array}{l}\text { Oral morphine } \\
\qquad n=77\end{array}$ & $\begin{array}{c}\text { Ibuprofen } \\
n=77\end{array}$ & $p$ value* \\
\hline First dose & & & 0.2 \\
\hline Before dose & $3(2-4)$ & $3(2-3)$ & \\
\hline After dose & $2(1-2)$ & $2(1-2)$ & \\
\hline Difference & $1(0-1)$ & $1(0-1)$ & \\
\hline Second dose & & & $>0.9$ \\
\hline Before dose & $3(2-4)$ & $3(2-4)$ & \\
\hline After dose & $2(1-3)$ & $2(1-2)$ & \\
\hline Difference & $1(0-2)$ & $1(0-1)$ & \\
\hline Third dose & & & 0.5 \\
\hline Before dose & $3(2-4)$ & $3(2-3)$ & \\
\hline After dose & $2(1-2.5)$ & $2(1-2)$ & \\
\hline Difference & $1(0-2)$ & $1(0-1)$ & \\
\hline Fourth dose & & & 0.9 \\
\hline Before dose & $3(1-4)$ & $3(2-4)$ & \\
\hline After dose & $2(1-2)$ & $2(1-2)$ & \\
\hline Difference & $1(0-1)$ & $1(0-1)$ & \\
\hline Fifth dose & & & 0.6 \\
\hline Before dose & $2(0-3)$ & $2.5(1-4)$ & \\
\hline After dose & $1(0-2)$ & $1(1-2)$ & \\
\hline Difference & $0(0-1)$ & $1(0-1)$ & \\
\hline Sixth dose & & & $>0.9$ \\
\hline Before dose & $2(0-3)$ & $2(0-3)$ & \\
\hline After dose & $1(0-2)$ & $1(0-2)$ & \\
\hline Difference & $0(0-1)$ & $0(0-1)$ & \\
\hline Seventh dose & & & 0.8 \\
\hline Before dose & $1(0-3)$ & $2(0-3)$ & \\
\hline After dose & $1(0-2)$ & $1(0-2)$ & \\
\hline Difference & $0(0-1)$ & $0(0-1)$ & \\
\hline Eighth dose & & & 0.6 \\
\hline Before dose & $0(0-3)$ & $2(0-2)$ & \\
\hline After dose & $0(0-1.5)$ & $1(0-2)$ & \\
\hline Difference & $0(0-1)$ & $0(0-1)$ & \\
\hline
\end{tabular}

pediatric inpatients, anxiety has been found to be highly correlated with postoperative pain. ${ }^{50}$

In our study, pre-intervention pain scores for the first 6 doses correlated with mild to moderate pain, ${ }^{43}$ but were associated with a perceived need for analgesia. ${ }^{41,51}$ For the first 6 doses, both agents produced a modest but clinically important reduction in pain. ${ }^{39}$ However, most post-intervention pain scores remained above the analgesic threshold recommended by the World Health Organization. ${ }^{51}$ Consistent with our work, neither ibuprofen nor oral morphine (nor a combination) has shown complete efficacy in children with musculoskeletal injury. ${ }^{52}$ We also found that more than $80 \%$ of children required analgesia in the first 24 hours. This result suggests that adequate pain management should be an important goal of care, even after minor outpatient surgery, and that more effective pharmacologic and nonpharmacologic strategies should be explored.

The most common adverse effects associated with morphine were drowsiness (48\%) and nausea (46\%), in keeping with previous studies. ${ }^{22,33,46}$ Among pediatric patients with obstructive sleep apnea who underwent tonsillectomy, Kelly and colleagues ${ }^{48}$ described a significantly higher frequency of oxygen desaturation with oral morphine. We chose not to measure this outcome because our sample included children with orthopedic pathology and excluded patients with obstructive sleep apnea. Concerns about adverse effects are prevalent (73\%) among caregivers of children who undergo outpatient surgery, ${ }^{3}$ as are concerns regarding the addictive potential of opioids. ${ }^{3,33}$ These concerns may be fueled by recent pediatric evidence of long-term risks ${ }^{53}$ and increased hospital admissions related to opioids. ${ }^{54}$ These reports, together with our findings, suggest that ibuprofen

Table 4: Adverse effects and requirement for breakthrough acetaminophen for participants who took at least 1 dose of the study drug

\begin{tabular}{|c|c|c|c|}
\hline \multirow[b]{2}{*}{ Outcome } & \multicolumn{2}{|c|}{$\begin{array}{l}\text { Study medication; } \\
\text { no. }(\%) \text { of participants` }\end{array}$} & \multirow[b]{2}{*}{$p$ value $\dagger$} \\
\hline & $\begin{array}{l}\text { Oral morphine } \\
\qquad n=65\end{array}$ & $\begin{array}{c}\text { Ibuprofen } \\
n=67\end{array}$ & \\
\hline $\begin{array}{l}\text { Receipt of breakthrough } \\
\text { acetaminophen }\end{array}$ & $18(28)$ & $26(39)$ & 0.2 \\
\hline $\begin{array}{l}\text { No. of breakthrough } \\
\text { acetaminophen doses } \\
\text { per patient, mean } \pm \text { SD }\end{array}$ & $0.7 \pm 1.3$ & $1.2 \pm 2$ & $0.09 \ddagger$ \\
\hline \multicolumn{4}{|l|}{ Adverse effects } \\
\hline Any & $45(69)$ & $26(39)$ & $<0.001$ \\
\hline Nausea & $30(46)$ & $13(19)$ & 0.002 \\
\hline Vomiting & $12(18)$ & $3(4)$ & 0.01 \\
\hline Drowsiness & $31(48)$ & $15(22)$ & 0.003 \\
\hline Dizziness & $20(31)$ & $4(6)$ & $<0.001$ \\
\hline Constipation & 9 (14) & $3(4)$ & 0.07 \\
\hline \multicolumn{4}{|c|}{$\begin{array}{l}\text { Note: } S D=\text { standard deviation. } \\
{ }^{*} \text { Except where stated otherwise. } \\
\text { †Pearson } \chi^{2} \text {, unless stated otherwise. } \\
\text { †Student } t \text { test. }\end{array}$} \\
\hline
\end{tabular}


may be more acceptable to caregivers who are managing children's pain at home.

Finally, access to analgesia is a barrier to effective postoperative pain management. ${ }^{20}$ Opioids, including morphine, typically require a prescription and a dispensing source. In contrast, ibuprofen is available without a prescription and is relatively inexpensive; furthermore, accidental ingestion and intentional overdose have less severe clinical consequences.

\section{Limitations}

The primary limitation of our study was the requirement for a fixed dosing interval $(6 \mathrm{~h})$ to preserve blinding. Differences in the duration of action between morphine (2-4 h) ${ }^{37}$ and ibuprofen $(4-8 \mathrm{~h})^{55}$ could have led to greater analgesic requirements in the morphine group. We found the opposite, however, in that more participants in the ibuprofen group reported using acetaminophen for breakthrough pain. More importantly, median preintervention pain scores were virtually identical in the 2 groups. Second, we included participants who underwent a variety of surgical procedures, which may have contributed to baseline heterogeneity. Our study was not powered for secondary outcomes, but we do not believe this imparted any substantial bias, because there were no large differences in discharge or preintervention pain scores or in the number of medication doses. Third, the Faces Pain Scale - Revised is a self-reporting tool not validated for home use. However, we believed it to be the single best approach to determining pain levels at home, and it is currently the recommended instrument for the age range of patients included in this study. ${ }^{56-59}$ In contrast to self-reported measures, observational assessments by health care providers, though arguably more objective, have been found to underestimate children's postoperative pain. ${ }^{40}$ Finally, our results may not be applicable to children who have undergone surgical procedures associated with greater than moderate levels of pain.

\section{Conclusion}

Both oral morphine and ibuprofen were associated with clinically significant pain reduction in children who underwent minor outpatient orthopedic surgery. Morphine did not provide superior analgesia, but was associated with significantly more adverse effects, making ibuprofen a better analgesic option. Importantly, pain was not completely managed by either intervention. Future work should explore whether combinations of non-opioid analgesics, more potent opioids with fewer adverse effects or nonpharmacologic therapies offer greater benefit, particularly for more severe pain.

\section{References}

1. Segerdahl M, Warren-Stomberg M, Rawal N, et al. Children in day surgery: clinical practice and routines. The results from a nation-wide survey. Acta Anaesthesiol Scand 2008;52:821-8.

2. Brown R, Fortier MA, Zolghadr S, et al. Postoperative pain management in children of Hispanic origin: a descriptive cohort study. Anesth Analg 2016;122:497-502.

3. Rony RYZ, Fortier MA, Chorney JM, et al. Parental postoperative pain management: attitudes, assessment, and management. Pediatrics 2010;125:e1372-8.

4. Nikanne E, Kokki H, Tuovinen K. Postoperative pain after adenoidectomy in children. Br J Anaesth 1999;82:886-9.
5. Kokki H, Ahonen R. Pain and activity disturbance after paediatric day case adenoidectomy. Paediatr Anaesth 1997;7:227-31.

6. Finley GA, McGrath PJ, Forward SP, et al. Parents' management of children's pain following 'minor' surgery. Pain 1996;64:83-7.

7. Wiggins SA, Foster RL. Pain after tonsillectomy and adenoidectomy: "Ouch it did hurt bad." Pain Manag Nurs 2007;8:156-65.

8. Kankkunen $P$, Vehviläinen-Julkunen K, Pietilä AM, et al. Parents' perceptions and use of analgesics at home after children's day surgery. Paediatr Anaesth 2003;13:132-40.

9. Fortier MA, MacLaren JE, Martin SR, et al. Pediatric pain after ambulatory surgery: Where's the medication? Pediatrics 2009;124:e588-95.

10. Zisk RY, Grey M, Medoff-Cooper B, et al. The squeaky wheel gets the grease: parental pain management of children treated for bone fractures. Pediatr Emerg Care 2008;24:89-96.

11. Coley KC, Williams BA, DaPos SV, et al. Retrospective evaluation of unanticipated admissions and readmissions after same day surgery and associated costs. J Clin Anesth 2002;14:349-53.

12. Sutters KA, Miaskowski C. Inadequate pain management and associated mor bidity in children at home after tonsillectomy. J Pediatr Nurs 1997;12:178-85.

13. Panneerselvam E, Balasubramanian S, Krishnakumar Raja VB, et al. 'Plain lignocaine' vs. 'lignocaine with vasoconstrictor' - comparative evaluation of pain during administration and post-extraction wound healing by a double blinded randomized controlled clinical trial. Acta Odontol Scand 2016;74:374-9.

14. Taddio A, McGrath P, Finley A. Effects of early pain experience: the human liter ature. Prog Pain Res Manag 1999;13:57-74.

15. Weisman SJ, Bernstein B, Schechter NL. Consequences of inadequate analgesia during painful procedures in children. Arch Pediatr Adolesc Med 1998;152:147-9.

16. Pate JT, Blount RL, Cohen LL, et al. Childhood medical experience and temperament as predictors of adult functioning in medical situations. Child Health Care 1996;25:281-98.

17. Sutters KA, Miaskowski C, Holdridge-Zeuner D, et al. A randomized clinical trial of the efficacy of scheduled dosing of acetaminophen and hydrocodone for the management of postoperative pain in children after tonsillectomy. Clin J Pain 2010;26:95-103.

18. Sutters KA, Miaskowski C, Holdridge-Zeuner D, et al. A randomized clinical trial of the effectiveness of a scheduled oral analgesic dosing regimen for the management of postoperative pain in children following tonsillectomy. Pain 2004; 110:49-55.

19. Rømsing J, Hertel S, Harder A, et al. Examination of acetaminophen for outpatient management of postoperative pain in children. Paediatr Anaesth 1998; 8:235-9.

20. Dorkham MC, Chalkiadis GA, von Ungern Sternberg BS, et al. Effective post operative pain management in children after ambulatory surgery, with a focus on tonsillectomy: barriers and possible solutions. Paediatr Anaesth 2014;24:239-48.

21. Clark E, Plint AC, Correll R, et al. A randomized, controlled trial of acetaminophen, ibuprofen, and codeine for acute pain relief in children with musculoskeletal trauma. Pediatrics 2007;119:460-7.

22. Poonai N, Bhullar G, Lin K, et al. Oral administration of morphine versus ibuprofen to manage postfracture pain in children: a randomized trial. CMAJ 2014; 186:1358-63.

23. Wille C, Bocquet N, Cojocaru B, et al. Oral morphine administration for children's traumatic pain [article in French]. Arch Pediatr 2005;12:248-53.

24. Ciszkowski C, Madadi P, Phillips MS, et al. Codeine, ultrarapid-metabolism genotype, and postoperative death. N Engl J Med 2009;361:827-8.

25. Voronov P, Przybylo HJ, Jagannathan N. Apnea in a child after oral codeine: a genetic variant - an ultra-rapid metabolizer. Paediatr Anaesth 2007;17:684-7.

26. Safety review update of codeine use in children; new Boxed Warning and Contraindication on use after tonsillectomy and/or adenoidectomy. Silver Spring (MD): US Food and Drug Administration; 2013. Available: www.fda.gov/downloads/ Drugs/DrugSafety/UCM339116.pdf (accessed 2017 Jan. 28).

27. Health Canada's review recommends codeine only be used in patients aged 12 and over. Ottawa: Health Canada; [updated 2016 July 28]. Available: http://healthy canadians.gc.ca/recall-alert-rappel-avis/hc-sc/2013/33915a-eng.php (accessed 2017 Jan. 28).

28. Shum S, Lim J, Page T, et al. An audit of pain management following pediatric day surgery at British Columbia Children's Hospital. Pain Res Manag 2012;17:328-34.

29. McGrath B, Elgendy H, Chung F, et al. Thirty percent of patients have moderate to severe pain $24 \mathrm{hr}$ after ambulatory surgery: a survey of 5703 patients. Can J Anaesth 2004;51:886-91. 
30. National Survey of Ambulatory Surgery. Survey results and products. Atlanta: Centers for Disease Control and Prevention; 2015. Available: https://www.cdc. gov/nchs/nsas/nsas_products.htm (accessed 2017 Jan. 12).

31. Kircher J, Drendel AL, Newton AS, et al. Pediatric musculoskeletal pain in the emergency department: a medical record review of practice variation. CJEM 2014;16:449-57.

32. Lewis ET, Cucciare MA, Trafton JA. What do patients do with unused opioid medications? Clin J Pain 2014;30:654-62.

33. Abou-Karam M, Dubé S, Kvann HS, et al. Parental report of morphine use at home after pediatric surgery. J Pediatr 2015;167:599-604.e1-2.

34. Simon R. Optimal two-stage designs for phase II clinical trials. Control Clin Trials 1989;10:1-10

35. Bieri D, Reeve RA, Champion GD, et al. The Faces Pain Scale for the self-assessment of the severity of pain experienced by children: development, initial validation, and preliminary investigation for ratio scale properties. Pain 1990;41: 139-50.

36. Beale JP, Oglesby AJ, Jones A, et al. Comparison of oral and intravenous morphine following acute injury in children. Eur J Emerg Med 2001;8:271-4.

37. Zernikow B, Michel E, Craig F, et al. Pediatric palliative care: use of opioids for the management of pain. Paediatr Drugs 2009;11:129-51.

38. Tucci JBE, Darwiche R, Medos Z, et al. Paracetamol and ibuprofen for paediatric pain and fever. J Pharm Pract Res 2009;39:223-5.39. Hicks CL, von Baeyer $\mathrm{CL}$, Spafford PA, et al. The Faces Pain Scale-Revised: toward a common metric in pediatric pain measurement. Pain 2001;93:173-83.

40. de Tovar C, Von Baeyer CL, Wood C, et al. Postoperative self-report of pain in children: interscale agreement, response to analgesic, and preference for a faces scale and a visual analogue scale. Pain Res Manag 2010;15:163-8.

41. Gauthier JC, Finley GA, McGrath PJ. Children's self-report of postoperative pain intensity and treatment threshold: determining the adequacy of medication. Clin J Pain 1998;14:116-20.

42. Stinson J, Yamada J, Dickson A, et al. Review of systematic reviews on acute procedural pain in children in the hospital setting. Pain Res Manag 2008;13:51-7.

43. Tsze DS, Hirschfeld G, Dayan PS, et al. Defining no pain, mild, moderate, and severe pain based on the Faces Pain Scale-Revised and Color Analog Scale in children with acute pain. Pediatr Emerg Care 2016 May 25 [Epub ahead of print].

44. Bulloch B, Tenenbein M. Assessment of clinically significant changes in acute pain in children. Acad Emerg Med 2002;9:199-202.
45. Altman D, Machin D, Bryant T, et al., editors. Statistics with confidence: confidence intervals and statistical guidelines. John Wiley \& Sons; 2013.

46. Duedahl TH, Hansen EH. A qualitative systematic review of morphine treatment in children with postoperative pain. Paediatr Anaesth 2007;17:756-74

47. O'Hara M, McGrath PJ, D'Astous J, et al. Oral morphine versus injected meperidine (Demerol) for pain relief in children after orthopedic surgery. J Pediatr Orthop 1987;7:78-82.

48. Kelly LE, Sommer DD, Ramakrishna J, et al. Morphine or ibuprofen for posttonsillectomy analgesia: a randomized trial. Pediatrics 2015;135:307-13.

49. Michelet D, Andreu-Gallien J, Bensalah T, et al. A meta-analysis of the use of nonsteroidal antiinflammatory drugs for pediatric postoperative pain. Anesth Analg 2012;114:393-406.

50. Rullander AC, Lundström M, Lindkvist M, et al. Stress symptoms among adolescents before and after scoliosis surgery: correlations with postoperative pain. J Clin Nurs 2016;25:1086-94.

51. Brennan F, Carr DB, Cousins M. Pain management: a fundamental human right. Anesth Analg 2007;105:205-21.

52. Le May S, Ali S, Plint A, et al. A randomized controlled trial on oral analgesic utilization for children presenting with a musculoskeletal trauma in the emergency department. Paediatr Child Health 2016;21:E53.

53. Miech R, Johnston L, O'Malley PM, et al. Prescription opioids in adolescence and future opioid misuse. Pediatrics 2015;136:e1169-77.

54. Gaither JR, Leventhal JM, Ryan SA, et al. National trends in hospitalizations for opioid poisonings among children and adolescents, 1997 to 2012. JAMA Pediatr 2016;170:1195-1201.

55. Repchinsky C, Welbanks L, Bisson R, editors. Compendium of pharmaceuticals and specialties. Ottawa: Canadian Pharmacists Association; 2002.

56. McGrath PJ, Walco GA, Turk DC, et al. Core outcome domains and measures for pediatric acute and chronic/recurrent pain clinical trials: PedIMMPACT recommendations. J Pain 2008;9:771-83.

57. Drendel AL, Brousseau DC, Gorelick MH. Pain assessment for pediatric patients in the emergency department. Pediatrics 2006;117:1511-8.

58. Drendel ALKB, Ali S. Pain assessment for children: overcoming challenges and optimizing care. Pediatr Emerg Care 2011;27:773-81.

59. Stinson JNKT, Yamada J, Gill N, et al. Systematic review of the psychometric properties, interpretability and feasibility of self-report pain intensity measures for use in clinical trials in children and adolescents. Pain 2006;125:143-57.

\section{Competing interests: None declared.}

This article has been peer reviewed.

Affiliations: Division of Emergency Medicine (Poonai, Zhu, Lepore), London Health Sciences Centre; Department of Paediatrics (Poonai, Datoo, Greff, Rieder) and Department of Surgery (Cashin, Bartley), Schulich School of Medicine and Dentistry, Western University, London, Ont.; Department of Pediatrics (Ali), Faculty of Medicine and Dentistry, Women and Children's Health Research Institute, University of Alberta, Edmonton, Alta.; Children's Hospital of Wisconsin (Drendel), Milwaukee, Wis.
Contributors: Naveen Poonai was the primary investigator and was responsible for designing the study, interpreting and analyzing the data and writing the manuscript. Natasha Datoo, Megan Cashin and Debra Bartley were responsible for designing the study, overseeing data collection and writing the Methods, Results and Interpretation sections of the manuscript. Samina Ali, Amy Drendel and Michael Rieder made extensive contributions to the design of the study, interpretation of the data and revision of the manuscript. Rongbo Zhu was responsible for tracking participants and data entry and contributed to writing the Methods and Results sections of the manuscript. Natasha Lepore and Michael Greff were responsible for participant recruit- ment, data collection and interpretation, and contributions to writing the Introduction and Methods sections of the manuscript. All of the authors gave final approval of the version to be published and agreed to be accountable for all aspects of the work.

Funding: This study was funded by a Schulich Research Opportunities Grant from Western University, London, Ont.

Data sharing: All portions of the data are available for sharing, upon contact with the corresponding author.

Accepted: June 7, 2017

Correspondence to: Naveen Poonai, naveen. poonai@lhsc.on.ca 